\title{
Design and rationale of the MR-INFORM study: stress perfusion MRI to guide the management of patients with stable coronary artery disease
}

\author{
Shazia T Hussain ${ }^{1 *}$, Matthias Paul ${ }^{1}$, Sven Plein ${ }^{2}$, Gerry P McCann ${ }^{3}$, Ajay Shah ${ }^{4}$, Amedeo Chiribiri ${ }^{1}$, Geraint Morton ${ }^{1}$, \\ Andreas Schuster ${ }^{1}$, Mark Westwood ${ }^{5}$, Divaka Perera ${ }^{4}$, Michael Marber $^{4}$, Eike Nagel ${ }^{1}$
}

From 15th Annual SCMR Scientific Sessions

Orlando, FL, USA. 2-5 February 2012

\section{Background}

Coronary angiography and the extent of coronary luminal stenosis has historically been the main factor used in guiding decisions regarding revascularisation in patients with stable coronary artery disease. More recently, revascularisation based on invasive fractional flow reserve (FFR) measurements has been shown to result in a significant benefit for event free survival. Cardiac magnetic resonance (CMR) perfusion imaging has been shown to be superior to nuclear perfusion imaging and has the potential to become the non-invasive test of choice.

\section{Methods}

The MR-INFORM study is a prospective, multi-centre, randomized controlled, non-inferiority, outcome trial. It will compare the efficacy of the two investigative strategies for the management of patients with suspected coronary artery disease. Patients presenting with stable angina are randomized into two groups: The FFRINFORMED and the MR-INFORMED group (Figure 1).

All patients undergo CMR perfusion scanning at $1.5 \mathrm{~T}$ (various vendors) at baseline. The patients in the MRINFORMED arm of the trial will have their subsequent management based on the results of the CMR scan. Those patients with significant ischaemia will have coronary angiography and revascularisation guided by the results of the MR scan i.e stenting in arteries that demonstrate ischaemia . All patients with non-significant ischaemia will have medical therapy optimized. The baseline scan in the FFR-INFORMED arm will remain

${ }^{1}$ Division of imaging sciences and Biomedical engineering, kings College, London, UK

Full list of author information is available at the end of the article blinded and the patient will go on to have coronary angiography with FFR measurement in those arteries with a stenosis of $40-99 \%$. The revascularisation decision in this group will be based on an FFR $<0.8$ below which a stenosis is physiologically significant. All patients will have a cardiovascular risk assessment at

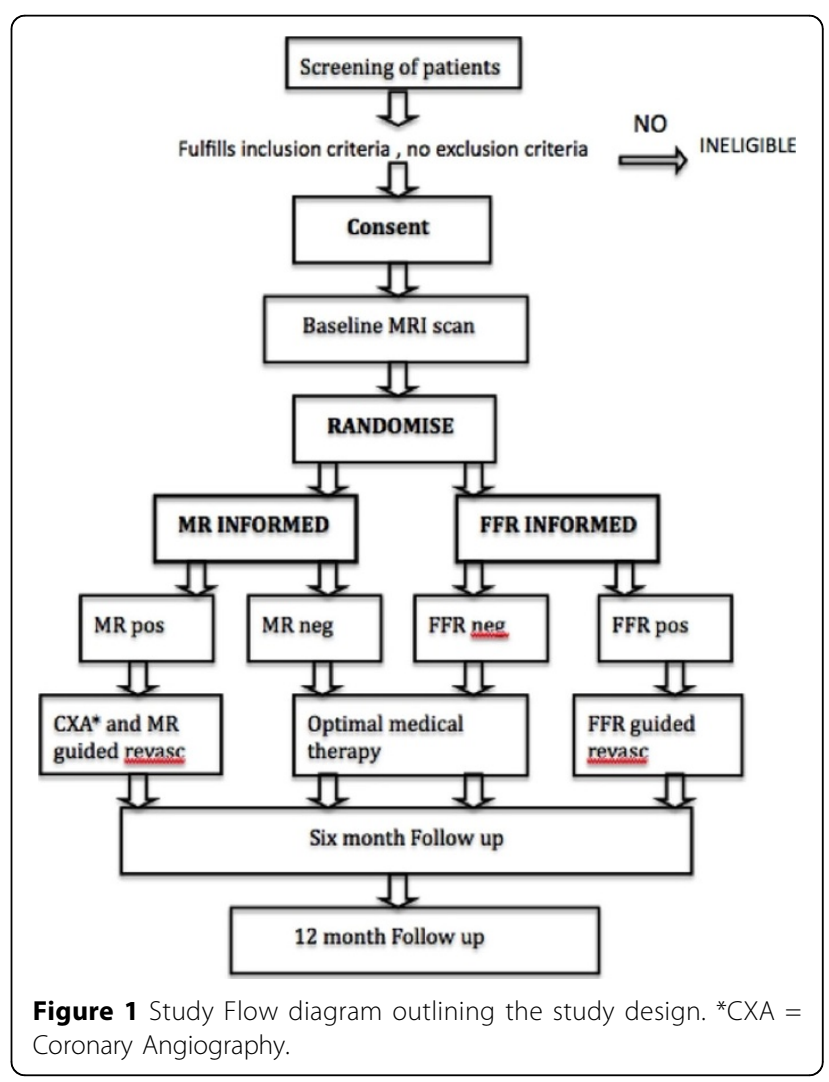

C 2012 Hussain et al; licensee BioMed Central Ltd. This is an open access article distributed under the terms of the Creative Commons Attribution License (http://creativecommons.org/licenses/by/2.0), which permits unrestricted use, distribution, and reproduction in any medium, provided the original work is properly cited. 
Table 1 Detailed definition of end-points

\begin{tabular}{ccc}
\hline End Point & & Definition \\
\hline Death & & All cause mortality \\
\hline $\begin{array}{c}\text { Myocardial } \\
\text { Infarction }\end{array}$ & Spontaneous & $\begin{array}{c}\text { Elevation of CK or Troponin above baseline with symptoms of ischaemia, ECG changes or imaging evidence of } \\
\text { loss of myocardium }\end{array}$ \\
\hline $\begin{array}{c}\text { Myocardial } \\
\text { Infarction }\end{array}$ & $\begin{array}{c}\text { Peri- } \\
\text { procedural }\end{array}$ & $\begin{array}{c}\text { CKMB }>3 X \text { ULN- upper limit of normal (post PCl 12-24hrs) CKMB }>5 X \text { ULN (post CABG 24-72 hours) plus new Q } \\
\text { waves or LBBB, new native vessel or graft occlusion, imaging evidence of loss of viable myocardium }\end{array}$ \\
\hline $\begin{array}{c}\text { Repeat } \\
\text { revascularisation }\end{array}$ & Repeat PCl or CABG of the target lesion performed for restenosis or other complication of the target lesion (from \\
$5 \mathrm{~mm}$ proximal to 5mm distal to the stent)
\end{tabular}

baseline, 6 months and 12 months and their medical therapy is optimized.

The principal hypothesis is that selecting patients with stable angina for revascularisation and optimal medical therapy (OMT) or OMT alone based on CMR myocardial perfusion is non-inferior to selecting patients based on routine coronary angiography and fractional flow reserve (FFR) in terms of subsequent major adverse cardiac events.

The primary end-point will be the composite of major adverse cardiac events at one year, defined as death, myocardial infarction and repeat revascularisation (table 1).

\section{Results}

In recruitment phase.

\section{Conclusions}

The MR-INFORM trial will compare the role of MR perfusion with routine coronary angiography and fractional flow measurements for guiding the management of patients with stable angina and an intermediate to high likelihood of coronary artery disease. Noninferiority of MR perfusion imaging to the current invasive reference standard (FFR) would establish MR perfusion imaging as an attractive non-invasive alternative to current diagnostic pathways. The results will help to inform national and international guidelines on the investigation and management of coronary artery disease, and ultimately lead to improved patient care.

\section{Funding}

Biomedical Research Centre (BRC), Bayer Schering Pharma.

\footnotetext{
Author details

${ }^{1}$ Division of imaging sciences and Biomedical engineering, kings College, London, UK. ${ }^{2}$ Multidisciplinary Cardiovascular Research Centre, University of Leeds, Leeds, UK. ${ }^{3} \mathrm{NIHR}$ Leicester Cardiovascular Biomedical Research Unit, University of Leicester, Leicester, UK. ${ }^{4}$ Cardiovascular Dept, King's College, London, UK. ${ }^{5}$ Cardiology Dept, london Chest Hospital, London, UK.
}

Published: 1 February 2012
doi:10.1186/1532-429X-14-S1-019

Cite this article as: Hussain et al:: Design and rationale of the MRINFORM study: stress perfusion MRI to guide the management of patients with stable coronary artery disease. Journal of Cardiovascular Magnetic Resonance 2012 14(Suppl 1):019.
Submit your next manuscript to BioMed Central and take full advantage of:

- Convenient online submission

- Thorough peer review

- No space constraints or color figure charges

- Immediate publication on acceptance

- Inclusion in PubMed, CAS, Scopus and Google Scholar

- Research which is freely available for redistribution

Submit your manuscript at www.biomedcentral.com/submit 